Check for updates

Cite this: RSC Adv., 2017, 7, 47073

\title{
Hyperhalogen properties of early-transition-metal borates $\uparrow$
}

\author{
Jia-Yuan Liu, ${ }^{a}$ Hai-Di Ma, ${ }^{a}$ Yan-bo Sun, ${ }^{a}$ Ying Li, ${ }^{a}$ Wei-Ming Sun, (D) bi Wu (D) *a \\ and Zhi-Ru Li ${ }^{\mathrm{a}}$
}

The equilibrium structures, stability and magnetic properties of $\mathrm{Sc}\left(\mathrm{BO}_{2}\right)_{n}^{-10}(n=1-4)$ clusters were investigated on the basis of density functional theory calculations. The $\mathrm{BO}_{2}$ ligands prefer to stretch out in the most stable $\mathrm{Sc}\left(\mathrm{BO}_{2}\right)_{n}{ }^{-}$anions but tend to come together in the lowest-lying $\mathrm{Sc}\left(\mathrm{BO}_{2}\right)_{4}$ structure. According to the MP2 results, the $\mathrm{Sc}\left(\mathrm{BO}_{2}\right)_{4}{ }^{-}$species could be classified as hyperhalogen anions since they have larger vertical electron detachment energies (VDEs, 5.44-8.85 eV) than that of the superhalogen anion $\mathrm{BO}_{2}{ }^{-}$. With titanium and vanadium playing the role of central atom, the $\mathrm{Ti}\left(\mathrm{BO}_{2}\right)_{n}{ }^{-1}$ ${ }^{0}(n=1-5)$ and $\mathrm{V}\left(\mathrm{BO}_{2}\right)_{n}{ }^{-10}(n=1-6)$ clusters were studied in a similar manner. In these cases, the central transition metal atoms are inclined to keep their intrinsic spin. In addition, the hyperhalogen

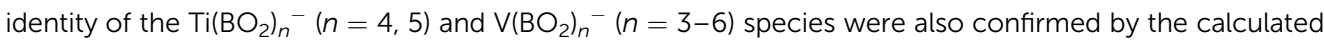
VDE values.

Received 14th September 2017 Accepted 26th September 2017

DOI: $10.1039 / \mathrm{c} 7 \mathrm{ra10238k}$

rsc.li/rsc-advances

\section{Introduction}

It is well-known that halogen atoms possess the highest electron affinities (EAs) in the periodic table, and the chlorine atom possesses the maximum value, namely $3.61 \mathrm{eV} .{ }^{1}$ Atoms and clusters with high EA usually show remarkable oxidation capacity in chemical reactions. Bartlett and co-workers found that $\mathrm{PtF}_{6}$ could even oxidize a Xe atom, ${ }^{2}$ and then confirmed that the $\mathrm{PtF}_{6}$ molecule possesses a very high EA of $6.8 \mathrm{eV} .^{3}$ Such molecules that have higher EAs than the chlorine atom were termed superhalogen by Boldyrev and Gutsev in $1981 .{ }^{4}$ Besides, they recommended a simple formula $\mathrm{MX}_{k+1}$ for constructing superhalogens, where $\mathrm{M}$ is a main group or transition metal atom, $\mathrm{X}$ is a halogen atom, and $k$ is the maximal formal valence of M. ${ }^{4}$ The first experimental evidence of such species, namely $\mathrm{MX}_{2}{ }^{-}(\mathrm{M}=\mathrm{Li}$, Na, and $\mathrm{X}=\mathrm{Cl}, \mathrm{Br}, \mathrm{I})$, was obtained by Wang's group in 1999. ${ }^{5}$ Afterwards, an increasing number of superhalogen anions have been theoretically predicted or experimentally detected, such as $\mathrm{MX}_{3}{ }^{-}(\mathrm{M}=\mathrm{Be}, \mathrm{Mg}, \mathrm{Ca} ; \mathrm{X}=\mathrm{Cl}, \mathrm{Br})^{6-8}$ and $\mathrm{MCl}_{4}{ }^{-}(\mathrm{M}=\mathrm{Sc}, \mathrm{Y}, \mathrm{La}) \cdot{ }^{9}$ Recently, many kinds of superhalogens that are beyond the $\mathrm{MX}_{k+1}$ formula have been proposed and characterized. To facilitate extra-electron delocalization, multinuclear superhalogen anions have been designed such as $\mathrm{P}_{2} \mathrm{~F}_{11}{ }^{-}$and $\mathrm{As}_{2} \mathrm{~F}_{11}{ }^{-10}{ }^{10} \mathrm{Mg}_{2} \mathrm{~F}_{5}{ }^{-11}, \mathrm{Al}_{2} \mathrm{~F}_{7}{ }^{-10}$ and

Institute of Theoretical Chemistry, Laboratory of Theoretical and Computational Chemistry, Jilin University, Changchun 130023, China. E-mail: wud@jlu.edu.cn

${ }^{b}$ Department of Basic Chemistry, The School of Pharmacy, Fujian Medical University, Fuzhou 350108, China

$\dagger$ Electronic supplementary information (ESI) available: Selected molecular orbitals of the studied borate anions, and VDE values of some related cluster anions. See DOI: 10.1039/c7ra10238k
$\mathrm{H}_{12} \mathrm{~F}_{13}{ }^{-}{ }^{12}$ As a result, higher vertical electron detachment energy can be achieved. By introducing non-halogen ligands, the scope of superhalogen has been further extended to include the chalcogen-based $\mathrm{MnO}_{4},{ }^{13} \mathrm{CrO}_{4},{ }^{14} \mathrm{BO}_{2},{ }^{15} \mathrm{AlO}_{2},{ }^{16} \mathrm{VO}_{3}{ }^{16}$ $\mathrm{BrO}_{3},{ }^{17} \mathrm{IO}_{3},{ }^{17} \mathrm{IO}_{4},{ }^{17} \mathrm{BS}_{2},{ }^{18}$ and $\mathrm{BSO}^{18}$ molecules, and those involving electrophilic substituent, ${ }^{19}$ organic group,${ }^{20}$ and acidic functional group ${ }^{21}$ as ligands.

Superhalogens are strong electron-acceptors and can be used to oxidize systems with high ionization potential, such as benzene ${ }^{22}$ and small water clusters. ${ }^{23}$ They may combine with superalkalis to form ionic compounds that are predicted to possess excellent nonlinear optical response. ${ }^{24}$ Recent studies have also shown that $\mathrm{MnCl}_{3}$, one of the experimentally synthesized superhalogens, could be used to tune the electronic and magnetic properties of silicone, ${ }^{25}$ and that the $\mathrm{AlF}_{4}$ superhalogen can initiate a radical-substitution chain reaction as the trigger-compound. ${ }^{26}$ In 2015 , Jena predicted that superhalogens could serve as a bridge between complex metal hydrides and electrolytes in Li-ion battery. ${ }^{27}$ Soon after, the suitability of superhalogen salt for $\mathrm{Mg}$ battery electrolyte was experimentally proved. ${ }^{28}$ The extensive application prospects of superhalogens make them promising agents in chemistry and material science and attract more and more attention..$^{29,30}$

Hyperhalogens, another series of electronegative clusters whose EA values are even higher than those of their superhalogen ligands, were proposed by Jena and coworkers in $2010 .^{31} \mathrm{Au}\left(\mathrm{BO}_{2}\right)_{2}$ was reported as the first member of this type of molecules. Thereafter, the strategy of using superhalogen as ligands was employed to design a great many high EA species, e.g., $\mathrm{Cu}_{n}\left(\mathrm{BO}_{2}\right)_{m}(n, m=1,2),{ }^{32} \mathrm{Al}\left(\mathrm{BO}_{2}\right)_{n},{ }^{33} \mathrm{Ag}\left(\mathrm{BO}_{2}\right)_{2},{ }^{34} \mathrm{Na}\left(\mathrm{BF}_{4}\right)_{2},{ }^{35}$

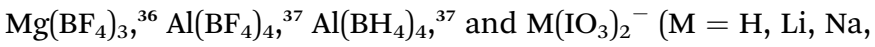


K). ${ }^{38}$ Furthermore, Jena et al. proposed the concept of "magnetic hyperhalogens" by studying the $\mathrm{Fe}\left(\mathrm{BO}_{2}\right)_{n}$ and $\mathrm{Mn}\left(\mathrm{BO}_{2}\right)_{n}$ clusters. ${ }^{39}$ Recently, two series of hyperhalogen anions involving planar and cage-like superhalogen ligands were reported, respectively, and the concept of aromatic hyperhalogen was brought forward as well. ${ }^{\mathbf{4 0 , 4 1}}$

In this work, theoretical investigation of borates of the first three subgroup elements, namely scandium, titanium, and vanadium, was presented. On the one hand, these transition metal (TM) elements have unfilled d orbitals, which may render the resulting compounds magnetism. On the other hand, they have multivalent properties, so it is interesting to make clear the minimum number of $\mathrm{BO}_{2}$ ligands they need to exhibit hyperhalogen character with. Besides, our study also aims to (1) reveal the geometrical feature of the resulting $\mathrm{Sc}\left(\mathrm{BO}_{2}\right)_{n}{ }^{-10}(n=$ $1-4), \mathrm{Ti}\left(\mathrm{BO}_{2}\right)_{n}{ }^{-/ 0}(n=1-5)$, and $\mathrm{V}\left(\mathrm{BO}_{2}\right)_{n}{ }^{-/ 0}(n=1-6)$ clusters; (2) detect their stability through examining their dissociation energies of predetermined dissociation pathways; (3) explore the spin state evolution of central atoms and VDE values of the $\mathrm{TM}\left(\mathrm{BO}_{2}\right)_{n}{ }^{-}(\mathrm{TM}=\mathrm{Sc}, \mathrm{Ti}, \mathrm{V})$ anions.

\section{Computational details}

With different spin multiplicity taken into account, the optimized geometries of the $\mathrm{Sc}\left(\mathrm{BO}_{2}\right)_{n}{ }^{-/ 0}(n=1-4), \operatorname{Ti}\left(\mathrm{BO}_{2}\right)_{n}{ }^{-/ 0}(n=$ 1-5), and $\mathrm{V}\left(\mathrm{BO}_{2}\right)_{n}{ }^{-10}(n=1-6)$ species were obtained by using the M06 functional ${ }^{42}$ of density functional theory. Frequency and natural bond orbital (NBO) analyses ${ }^{43}$ were performed at the same level. Single point energies were computed by using the second-order Møller-Plesset (MP2) method. For all calculations, the $6-311+\mathrm{G}(3 \mathrm{df})$ basis set was used for $\mathrm{B}$ and $\mathrm{O}$ atoms, while the Los Alamos set of the double-zeta type LANL2DZ basis set and effective core potential (ECP) were used for the Sc, Ti, and $\mathrm{V}$ atoms.

The vertical detachment energies (VDEs) of the $\mathrm{Sc}\left(\mathrm{BO}_{2}\right)_{n}{ }^{-}(n$ $=1-4), \mathrm{Ti}\left(\mathrm{BO}_{2}\right)_{n}{ }^{-}(n=1-5)$, and $\mathrm{V}\left(\mathrm{BO}_{2}\right)_{n}{ }^{-}(n=1-6)$ anions were obtained by two methods. First, the VDE values were indirectly computed as the energy difference between the neutral and the anion both at the anion's geometry by using the MP2 method. Second, the restricted outer valence Green function (OVGF) ${ }^{\mathbf{4 4 - 4 6}}$ method was used to estimate the VDE values. For all investigated anions, the pole strengths (PSs) are greater than 0.85 , justifying the validity of OVGF approximation. ${ }^{47}$ For comparison, the adiabatic detachment energy (ADE) of each anion was also obtained by using the MP2 method, which was computed as the difference in total energy between the neutral and anion at their respective optimized geometries.

All calculations were performed using the GAUSSIAN 09 program package. ${ }^{48}$ Dimensional plots of the molecular structures were generated with the GaussView program. ${ }^{49}$

\section{Results and discussion}

\section{1 $\mathrm{Sc}\left(\mathrm{BO}_{2}\right)_{n}{ }^{-}$and $\mathrm{Sc}\left(\mathrm{BO}_{2}\right)_{n}(n=1-4)$}

3.1.1 Equilibrium geometries and relative stability. We considered all possible configurations of $\mathrm{Sc}\left(\mathrm{BO}_{2}\right)_{n}{ }^{-}$and $\mathrm{Sc}\left(\mathrm{BO}_{2}\right)_{n}$ and show their optimized structures in Fig. 1 and 2, respectively. Their relative energies are listed in Tables 1 and 2, respectively. The nomenclature uses Arabic numeral from 1 to 4 to indicate the number of $\mathrm{BO}_{2}$ ligands in the $\mathrm{Sc}\left(\mathrm{BO}_{2}\right)_{n}{ }^{-}$clusters, followed by $\mathrm{a}, \mathrm{b}, \mathrm{c}$. .. indicating the increasing MP2 single point energy order of different isomers. As for the neutral $\mathrm{Sc}\left(\mathrm{BO}_{2}\right)_{n}$ series, their structures are named after corresponding anionic ones.

As shown in Fig. 1, isomer $1 \mathrm{a}$ of $\mathrm{ScBO}_{2}{ }^{-}$is linear and similar to the reported structures of $\mathrm{FeBO}_{2}, \mathrm{MnBO}_{2}$, and $\mathrm{MnBO}_{2}{ }^{-} \cdot{ }^{39}$ The other isomer $\mathbf{1 b}$ has $C_{2 \mathrm{v}}$ symmetry, where the $\mathrm{BO}_{2}$ ligand bends to $156.6^{\circ}$ and binds with the Sc atom via two $\mathrm{O}$ atoms. Both 1a and $\mathbf{1 b}$ have magnetic moment of $1 \mu_{\mathrm{B}}$. However, the neutral $\mathrm{ScBO}_{2}$ (see Fig. 2) has variable magnetism. The most stable isomer $1 \mathbf{a}^{\prime}$ of $\mathrm{ScBO}_{2}$ has a magnetic moment of $2 \mu_{\mathrm{B}}$, which is similar to the case of ScCl and ScF. ${ }^{50}$ Isomer $\mathbf{1 a}^{\prime \prime}$ also has a linear configuration, only it has a magnetic moment of $0 \mu_{\mathrm{B}}$ and slightly shorter Sc-O bond length of $1.867 \AA$. As for $\mathbf{1 b}^{\prime}$ and $\mathbf{1} \mathbf{b}^{\prime \prime}$, which share similar structural features with $\mathbf{1 b}$, they possess different Sc-O bond lengths (2.225 $\AA$ and $2.114 \AA$, respectively) and magnetic moments ( $2 \mu_{\mathrm{B}}$ and $0 \mu_{\mathrm{B}}$, respectively).

As one more $\mathrm{BO}_{2}$ ligand is introduced, four isomers have been obtained for both anionic $\mathrm{Sc}\left(\mathrm{BO}_{2}\right)_{2}{ }^{-}$and neutral $\mathrm{Sc}\left(\mathrm{BO}_{2}\right)_{2}$. The spin multiplicities of $\mathrm{Sc}\left(\mathrm{BO}_{2}\right)_{2}{ }^{-}$and $\mathrm{Sc}\left(\mathrm{BO}_{2}\right)_{2}$ are 1 and 2, respectively. 2a, the lowest-energy isomer of $\mathrm{Sc}\left(\mathrm{BO}_{2}\right)_{2}{ }^{-}$, has a linear structure, in which each $\mathrm{BO}_{2}$ ligand is attached to the middle Sc atom through a $\mathrm{Sc}-\mathrm{O}$ bond. The same case was reported for the ground states of $\mathrm{Mn}\left(\mathrm{BO}_{2}\right)_{2}{ }^{-}$and $\mathrm{Fe}\left(\mathrm{BO}_{2}\right)_{2}{ }^{-} \cdot{ }^{39}$ The Sc-O bond length (1.979 $\AA$ ) of $2 \mathrm{a}$ is slightly shorter than that of 1a $(2.006 \AA)$. Isomer $\mathbf{2 b}$ has a planar structure, where the two $\mathrm{BO}_{2}$ ligands combine with each other, forming a $\mathrm{B}_{2} \mathrm{O}_{4}$ unit that shows a similar structure to the recently reported $\left(\mathrm{BO}_{2}\right)_{2}{ }^{-}$ anion. ${ }^{51}$ In the next isomer $2 \mathrm{c}$, two $\mathrm{BO}_{2}$ ligands bind with the $\mathrm{Sc}$ atom via one and two Sc-O bonds, respectively. The $\angle \mathrm{O} 1 \mathrm{~B} 1 \mathrm{O} 2$ angle of $2 \mathrm{c}$ is $147.5^{\circ}$, indicating a larger ligand distortion relative to structure $\mathbf{1 b}$. As for the last isomer $\mathbf{2 d}$, it has a $D_{2 \mathrm{~d}^{-}}$ symmetric structure where each $\mathrm{BO}_{2}$ unit is linked to the center $\mathrm{Sc}$ atom by two Sc-O bonds. The Sc atom is coplanar with each $\mathrm{BO}_{2}$ ligand in this structure and the two $\mathrm{BO}_{2}$ planes are perpendicular to each other. The $\angle \mathrm{OBO}$ angle in $2 \mathrm{~d}$ is $148.5^{\circ}$, which is close to that of 2c. From Fig. 2 and Table 2, the neutral $\mathrm{Sc}\left(\mathrm{BO}_{2}\right)_{2}$ isomers share similar structures and the same total energy order with their corresponding anions.

$\mathrm{Sc}\left(\mathrm{BO}_{2}\right)_{3}{ }^{-}$and $\mathrm{Sc}\left(\mathrm{BO}_{2}\right)_{3}$ have magnetic moments of $1 \mu_{\mathrm{B}}$ and $0 \mu_{\mathrm{B}}$, respectively. Seven structures were obtained for $\operatorname{Sc}\left(\mathrm{BO}_{2}\right)_{3}{ }^{-}$, and the $D_{3 \mathrm{~h}}$-symmetric structure $\mathbf{3 a}$ is the most stable one. In 3a, each $\mathrm{BO}_{2}$ ligand binds with the center Sc atom via one $\mathrm{Sc}-\mathrm{O}$ bond of $1.990 \AA$ A. In contrast, a ScOBO quadrilateral forms in the rest isomers. The $C_{2 \mathrm{v}}$-symmetric isomer $\mathbf{3 b}$ can be viewed as one more $\mathrm{BO}_{2}$ ligand attaching to structure $2 \mathrm{c}$, which is supported by NBO analysis. Both isomers $\mathbf{3 c}$ and $\mathbf{3 d}$ can be obtained by

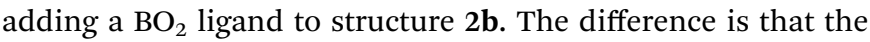
additional $\mathrm{BO}_{2}$ ligand bonds with the $\mathrm{Sc}$ atom via one $\mathrm{O}$ atom in the former but via two $\mathrm{O}$ atoms in the latter. In $C_{2 \mathrm{v}}$-symmetric 3e, three $\mathrm{BO}_{2}$ ligands get together and form a $\mathrm{B}_{3} \mathrm{O}_{6}$ unit, which is similar to the structure of $\left(\mathrm{BO}_{2}\right)_{3}{ }^{-} \cdot{ }^{51}$ In the next isomer $\mathbf{3 f}$, a $\mathrm{B}_{2} \mathrm{O}_{4}$ unit forms and is linked to Sc through three $\mathrm{Sc}-\mathrm{O}$ bonds. The least favorable structure of $\mathrm{Sc}\left(\mathrm{BO}_{2}\right)_{3}{ }^{-}$is $3 \mathrm{~g}$ with $C_{\mathrm{s}}$ 


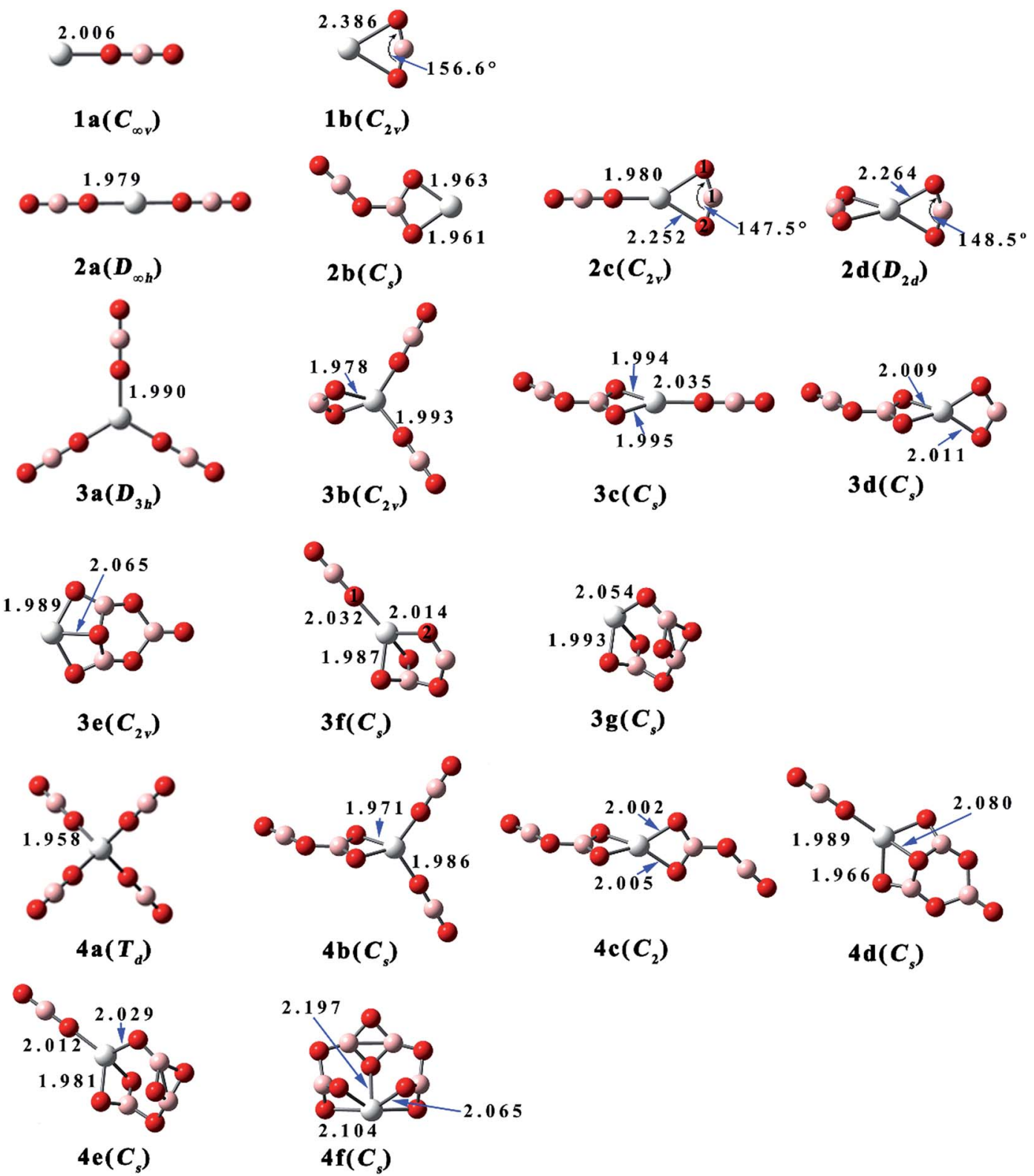

Fig. 1 Equilibrium structures and critical bond lengths (in $\AA$ ) of the $\mathrm{Sc}\left(\mathrm{BO}_{2}\right)_{n}{ }^{-}(n=1-4)$ clusters. (Color legend: $\mathrm{Sc}$, grey; O, red; $\mathrm{B}$, light pink. Symmetry in parentheses.)

symmetry, which contains a different $\mathrm{B}_{3} \mathrm{O}_{6}$ unit compared with 3e. As for neutral $\mathrm{Sc}\left(\mathrm{BO}_{2}\right)_{3}$, all isomers possess a similar structure to their corresponding anions but their stability follows a different order. The largest structural difference is found between $\mathbf{3 c}$ and its neutral counterpart, namely $\mathbf{3 \mathbf { c } ^ { \prime }}$ where one of the $\mathrm{BO}_{2}$ ligands deviates $45.7^{\circ}$ from the horizontal.

Six optimized configurations $\left(\mu_{\mathrm{B}}=0\right)$ were obtained for $\mathrm{Sc}\left(\mathrm{BO}_{2}\right)_{4}{ }^{-}$and all of them can be considered derived from the $\mathrm{Sc}\left(\mathrm{BO}_{2}\right)_{3}{ }^{-}$structures. The $T_{\mathrm{d}}$-symmetric $\mathbf{4 a}$ is the most stable isomer of $\mathrm{Sc}\left(\mathrm{BO}_{2}\right)_{4}{ }^{-}$, in which each $\mathrm{BO}_{2}$ ligand connects to the Sc atom via one $\mathrm{O}$ atom, forming four Sc-O bonds of $1.958 \AA$. The four $\mathrm{BO}_{2}$ ligands keep away from each other and retain their linear geometry in this isomer. In contrast, two or more $\mathrm{BO}_{2}$ units are combined together in the higher-lying isomers. Isomer 4b lies $6.9 \mathrm{kcal} \mathrm{mol}^{-1}$ higher in energy than 4a. It can be obtained by attaching one more $\mathrm{BO}_{2}$ ligand to the vertex boron atom of $3 \mathbf{b}$. With two $\mathrm{B}_{2} \mathrm{O}_{4}$ units linked to the Sc atom separately, the $C_{2}$-symmetric $4 \mathrm{c}$ is generated. A trimeric $\mathrm{BO}_{2}\left(\mathrm{~B}_{3} \mathrm{O}_{6}\right)$ unit forms in both $\mathbf{4 d}$ and $\mathbf{4 e}$ isomers, and the energy difference between them is $6.7 \mathrm{kcal} \mathrm{mol}^{-1}$. From Fig. 1, 4d and $4 \mathrm{e}$ basically inherit the structures of $\mathbf{3 e}$ and $\mathbf{3 g}$, respectively, apart from an additional $\mathrm{BO}_{2}$ ligand being attached to the Sc atom of their precursors. In the least stable isomer $\mathbf{4 f}$, four $\mathrm{BO}_{2}$ ligands polymerize to form a tetrameric $\mathrm{B}_{4} \mathrm{O}_{8}$, which is bound to the Sc atom through five $\mathrm{Sc}-\mathrm{O}$ bonds. Note that all anionic $\mathrm{Sc}\left(\mathrm{BO}_{2}\right)_{4}{ }^{-}$ have corresponding neutral $\mathrm{Sc}\left(\mathrm{BO}_{2}\right)_{4}$ structures $\left(\mu_{\mathrm{B}}=1\right)$, only the latter has different total energy order from the former. For instance, the most stable isomer of $\mathrm{Sc}\left(\mathrm{BO}_{2}\right)_{4}$, namely $\mathbf{4} \mathbf{d}^{\prime}$, has 


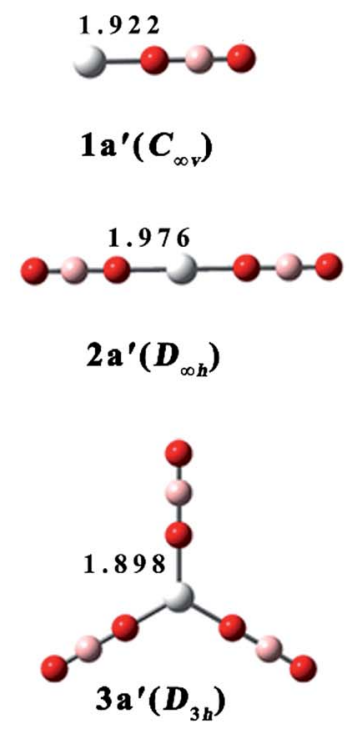

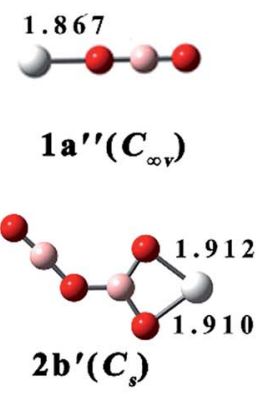
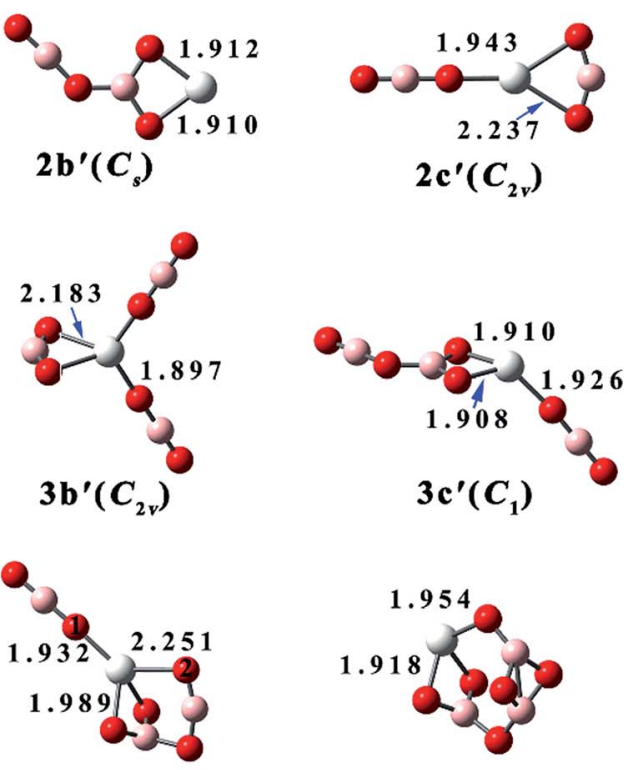

$3 \mathrm{f}^{\prime}\left(C_{s}\right)$
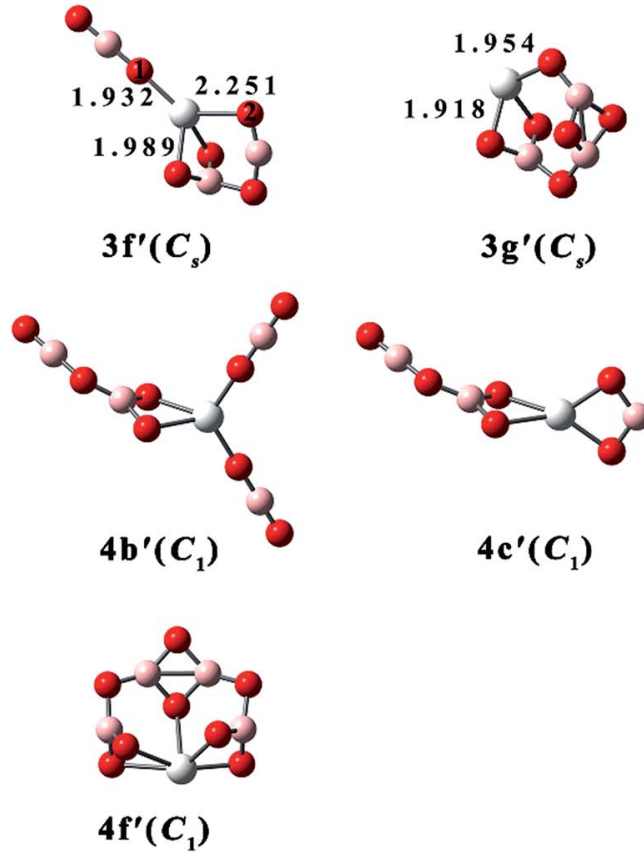

$3 g^{\prime}\left(C_{s}\right)$

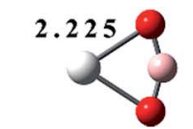

$1 b^{\prime}\left(C_{2 v}\right)$

$2 c^{\prime}\left(C_{2 v}\right)$
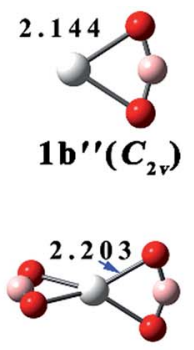

2d' $\left(D_{2 d}\right)$
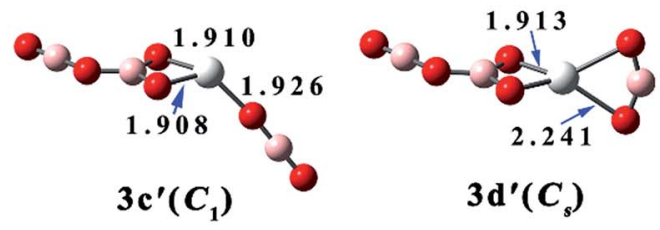

$3 \mathrm{~d}^{\prime}\left(C_{s}\right)$
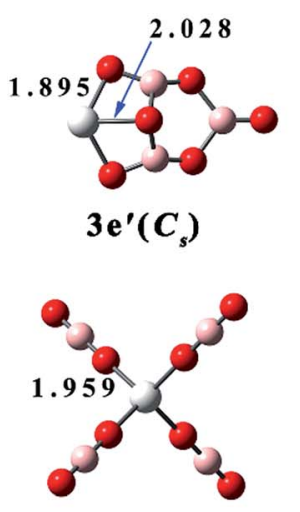

$4 a^{\prime}\left(T_{d}\right)$

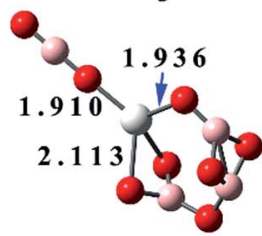

$4 \mathrm{e}^{\prime}\left(C_{s}\right)$

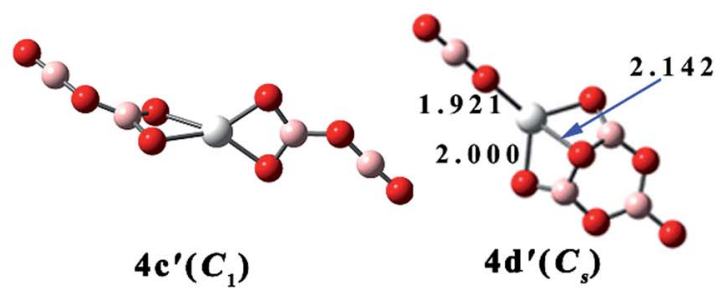

Fig. 2 Equilibrium structures and critical bond lengths (in $\AA$ ) of the $\mathrm{Sc}\left(\mathrm{BO}_{2}\right)_{n}(n=1-4)$ clusters. (Color legend: Sc, grey; O, red; $\mathrm{B}$, light pink. Symmetry in parentheses.)

a similar structure to $\mathbf{4 d}$, a low-lying isomer of $\mathrm{Sc}\left(\mathrm{BO}_{2}\right)_{4}{ }^{-}$. Meanwhile, the lowest-energy isomer of $\mathrm{Sc}\left(\mathrm{BO}_{2}\right)_{4}{ }^{-}$is corresponding to the least favorable configuration $\left(\mathbf{4 a}^{\prime}\right)$ of $\mathrm{Sc}\left(\mathrm{BO}_{2}\right)_{4}$. This reflects the fact that the loss of extra electron only slightly affects geometry of the studied anions, but varies their relative stability.

3.1.2 Dissociation energy. To explore the thermodynamic stability of the $\mathrm{Sc}\left(\mathrm{BO}_{2}\right)_{n}{ }^{-}$anions, two fragmentation paths were considered, namely $\mathrm{Sc}\left(\mathrm{BO}_{2}\right)_{n}{ }^{-} \rightarrow \mathrm{Sc}\left(\mathrm{BO}_{2}\right)_{n-1}+\mathrm{BO}_{2}{ }^{-}$and $\mathrm{Sc}\left(\mathrm{BO}_{2}\right)_{n}{ }^{-} \rightarrow \mathrm{Sc}\left(\mathrm{BO}_{2}\right)_{n-1}{ }^{-}+\mathrm{BO}_{2}$. The zero-point-corrected dissociation energies of the $\mathrm{Sc}\left(\mathrm{BO}_{2}\right)_{n}{ }^{-}$anions are listed in Table 1. From the table, these dissociation reactions are highly endothermic. Hence, all $\mathrm{Sc}\left(\mathrm{BO}_{2}\right)_{n}{ }^{-}$anions are stable when it comes to emission of a $\mathrm{BO}_{2}{ }^{-}$or $\mathrm{BO}_{2}$ fragment. Besides, the dissociation of a neutral $\mathrm{BO}_{2}$ ligand requires more energy than detaching a $\mathrm{BO}_{2}{ }^{-}$anion from $\mathrm{Sc}\left(\mathrm{BO}_{2}\right)_{n}{ }^{-}$. As far as the lowestenergy $\mathrm{Sc}\left(\mathrm{BO}_{2}\right)_{n}{ }^{-}$isomers are concerned, it gets more difficult for them to lose a $\mathrm{BO}_{2}{ }^{-}$unit as $n$ becomes larger. For neutral $\mathrm{Sc}\left(\mathrm{BO}_{2}\right)_{n}$, we also considered two fragmentation pathways, namely $\mathrm{Sc}\left(\mathrm{BO}_{2}\right)_{n} \rightarrow \mathrm{Sc}\left(\mathrm{BO}_{2}\right)_{n-1}+\mathrm{BO}_{2}$ and $\mathrm{Sc}\left(\mathrm{BO}_{2}\right)_{n} \rightarrow$ $\mathrm{Sc}\left(\mathrm{BO}_{2}\right)_{n-2}+\mathrm{B}_{2} \mathrm{O}_{4}$. From Table 2, their corresponding zeropoint-corrected dissociation energies vary in the range of $33.7-132.5 \mathrm{kcal} \mathrm{mol}^{-1}$ and $120.7-209.4 \mathrm{kcal} \mathrm{mol}^{-1}$, respectively, indicating the stability of $\mathrm{Sc}\left(\mathrm{BO}_{2}\right)_{n}$. It is also noted that there is not much chance for $\mathrm{Sc}\left(\mathrm{BO}_{2}\right)_{n}$ to eliminate a $\mathrm{B}_{2} \mathrm{O}_{4}$ dimer in view of the high dissociation energies. 
Table 1 Relative energy $\left(E_{\text {rel, }}\right.$ in $\left.\mathrm{kcal} \mathrm{mol}^{-1}\right)$, vertical detachment energies (VDEs, in eV), and adiabatic detachment energies (ADEs, in eV) of the

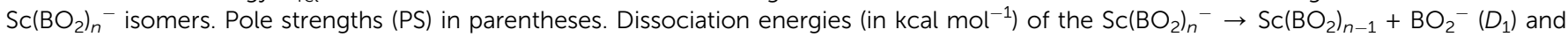
$\mathrm{Sc}\left(\mathrm{BO}_{2}\right)_{n}{ }^{-} \rightarrow \mathrm{Sc}\left(\mathrm{BO}_{2}\right)_{n-1}{ }^{-}+\mathrm{BO}_{2}\left(D_{2}\right)$ reactions

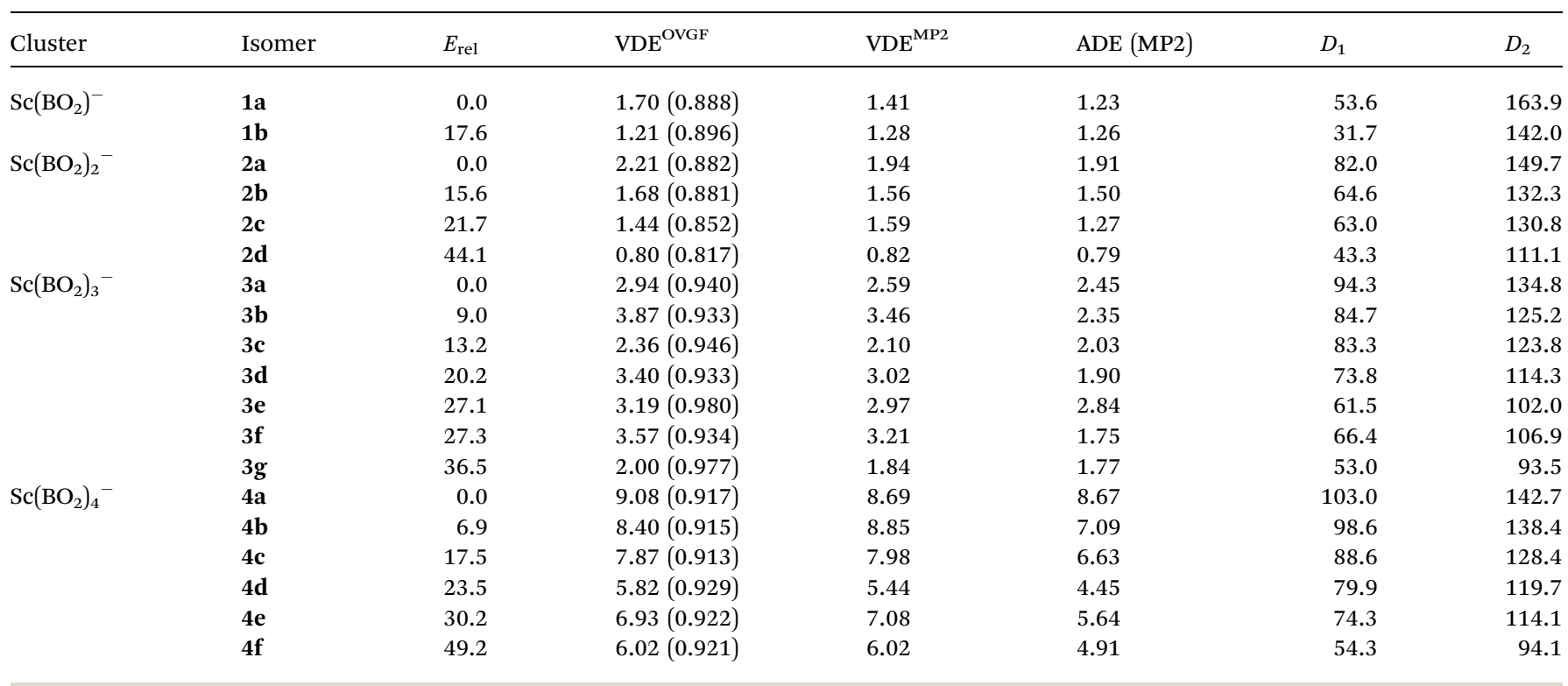

Table 2 Relative energy $\left(E_{\text {rel, }}\right.$ in $\left.\mathrm{kcal} \mathrm{mol}^{-1}\right)$ of the $\mathrm{Sc}\left(\mathrm{BO}_{2}\right)_{n}$ isomers and dissociation energies (in kcal mol${ }^{-1}$ ) of the $\mathrm{Sc}\left(\mathrm{BO}_{2}\right)_{n} \rightarrow \mathrm{Sc}\left(\mathrm{BO}_{2}\right)_{n-1}$ $+\mathrm{BO}_{2}\left(D^{\prime}{ }_{1}\right)$ and $\mathrm{Sc}\left(\mathrm{BO}_{2}\right)_{n} \rightarrow \mathrm{Sc}\left(\mathrm{BO}_{2}\right)_{n-2}+\mathrm{B}_{2} \mathrm{O}_{4}\left(D^{\prime}{ }_{2}\right)$ reactions

\begin{tabular}{|c|c|c|c|c|}
\hline Cluster & Isomer & $E_{\text {rel }}$ & $D_{1}^{\prime}$ & $D_{2}^{\prime}$ \\
\hline \multirow[t]{4}{*}{$\mathrm{Sc}\left(\mathrm{BO}_{2}\right)$} & $1 a^{\prime}-t$ & 0.0 & 112.2 & - \\
\hline & $1 a^{\prime}-\mathbf{s}$ & 10.2 & 121.3 & - \\
\hline & $1 b^{\prime}-t$ & 19.8 & 99.4 & - \\
\hline & $1 b^{\prime}-s$ & 28.4 & 108.8 & - \\
\hline \multirow[t]{4}{*}{$\mathrm{Sc}\left(\mathrm{BO}_{2}\right)_{2}$} & $2 \mathbf{a}^{\prime}$ & 0.0 & 122.5 & 206.8 \\
\hline & $2 \mathbf{b}^{\prime}$ & 6.1 & 124.0 & 208.3 \\
\hline & $2 c^{\prime}$ & 6.8 & 120.4 & 204.7 \\
\hline & $2 d^{\prime}$ & 18.1 & 111.7 & 196.1 \\
\hline \multirow[t]{7}{*}{$\mathrm{Sc}\left(\mathrm{BO}_{2}\right)_{3}$} & $3 \mathbf{a}^{\prime}$ & 0.0 & 130.7 & 207.7 \\
\hline & $3 \mathbf{b}^{\prime}$ & 6.8 & 125.3 & 202.2 \\
\hline & $3 c^{\prime}$ & 3.5 & 132.5 & 209.4 \\
\hline & $3 d^{\prime}$ & 7.5 & 127.6 & 204.5 \\
\hline & $3 \mathrm{e}^{\prime}$ & 35.9 & 101.3 & 178.2 \\
\hline & $3 \mathbf{f}^{\prime}$ & 11.2 & 122.4 & 199.3 \\
\hline & $3 g^{\prime}$ & 20.8 & 117.6 & 194.5 \\
\hline \multirow[t]{6}{*}{$\mathrm{Sc}\left(\mathrm{BO}_{2}\right)_{4}$} & $4 a^{\prime}$ & 73.8 & 33.7 & 120.7 \\
\hline & $4 \mathbf{b}^{\prime}$ & 44.4 & 44.3 & 131.3 \\
\hline & $4 c^{\prime}$ & 44.3 & 46.1 & 133.1 \\
\hline & $4 d^{\prime}$ & 0.0 & 82.1 & 169.1 \\
\hline & $4 \mathrm{e}^{\prime}$ & 34.2 & 50.6 & 137.6 \\
\hline & $\mathbf{4 f ^ { \prime }}$ & 36.4 & 54.1 & 141.1 \\
\hline
\end{tabular}

3.1.3 Hyperhalogen characteristics. Jena and coworkers have reported that MP2 is a reliable method for estimating the vertical detachment energies (VDEs) of metal borate anion and yields results close to those from the $\operatorname{CCSD}(\mathrm{T})$ method..$^{33}$ On the other hand, the OVGF method is also very popular in assessing the VDEs of anions..$^{5-8,10-12,19,21,33,50}$ Take the $\mathrm{ScCl}_{4}{ }^{-}$anion as an example. Its VDE value calculated by the OVGF method is $7.18 \mathrm{eV}$, which agrees quite well with the experimental result of 7.14 eV. ${ }^{9}$ Hence, the VDEs of the $\mathrm{Sc}\left(\mathrm{BO}_{2}\right)_{n}{ }^{-}$anions were obtained by using the MP2 and OVGF methods, respectively. Besides, the adiabatic detachment energies (ADEs) of $\mathrm{Sc}\left(\mathrm{BO}_{2}\right)_{n}{ }^{-}$ were also calculated at the MP2 level. All results are given in Table 1. From the table, the results of MP2 and OVGF calculations are basically consistent. According to the MP2 results, the $\mathrm{Sc}\left(\mathrm{BO}_{2}\right)_{4}{ }^{-}$anions exhibit high VDE values ranging from 5.44 to $8.85 \mathrm{eV}$, which are larger than the VDE of $4.46 \mathrm{eV}$ for the $\mathrm{BO}_{2}{ }^{-}$ anion. Therefore, the $\mathrm{Sc}\left(\mathrm{BO}_{2}\right)_{4}{ }^{-}$species could be classified as hyperhalogen anions. Among the $\mathrm{Sc}\left(\mathrm{BO}_{2}\right)_{4}{ }^{-}$anions, the first three isomers $4 \mathbf{4 a}-\mathbf{c}$ possess larger $\mathrm{VDE}^{\mathrm{MP} 2}$ values $(7.98-8.85 \mathrm{eV})$ than the rest ones $\mathbf{4 d - f}(5.44-7.08 \mathrm{eV})$. This could be attributed to the polymerization of $\mathrm{BO}_{2}$ units, which is a disadvantage for $\mathrm{Sc}\left(\mathrm{BO}_{2}\right)_{4}{ }^{-}$to distribute the extra negative charge. Besides, it can be seen from Table 1 that the VDE values show an increasing order of $\mathbf{1 a}<\mathbf{2 a}<\mathbf{3 a}<\mathbf{4 a}$, indicating the VDE dependence of $\mathrm{Sc}\left(\mathrm{BO}_{2}\right)_{n}{ }^{-}$on the number of $\mathrm{BO}_{2}$ ligands. In particular, the VDEs show a sharp increase from $\mathrm{Sc}\left(\mathrm{BO}_{2}\right)_{3}{ }^{-}$to $\mathrm{Sc}\left(\mathrm{BO}_{2}\right)_{4}{ }^{-}$, which can be related to the maximum valence state of +3 of the $\mathrm{Sc}$ atom.

For comparison, the previously reported VDE values of $\mathrm{Al}\left(\mathrm{BO}_{2}\right)_{n}{ }^{-},{ }^{33} \mathrm{Sc}\left(\mathrm{BH}_{4}\right)_{n}{ }^{-},{ }^{52}$ and $\mathrm{ScF}_{n}{ }^{-}$(ref. 50) are shown in ESI. $\dagger$ Given that $\mathrm{ScF}_{4}{ }^{-}$is a superhalogen anion with halogen as ligands, it is not surprising that it possesses a smaller VDE value of $7.74 \mathrm{eV}$ than that of $\mathrm{Sc}\left(\mathrm{BO}_{2}\right)_{4}{ }^{-}$(8.69 eV in the present work). Note that $\mathrm{Sc}\left(\mathrm{BO}_{2}\right)_{4}{ }^{-}$also outperforms other hyperhalogen anions. From Table $\mathrm{S} 1, \dagger$ the VDE value of $\mathrm{Sc}\left(\mathrm{BO}_{2}\right)_{4}{ }^{-}$is much larger than that of $\mathrm{Sc}\left(\mathrm{BH}_{4}\right)_{4}{ }^{-}(6.47 \mathrm{eV})$, although $\mathrm{BO}_{2}{ }^{-}$has a smaller VDE value compared with $\mathrm{BH}_{4}{ }^{-}(4.57 \mathrm{eV})$. Likewise, $\mathrm{Sc}\left(\mathrm{BO}_{2}\right)_{4}{ }^{-}$is probably a stronger oxidizing agent than $\mathrm{Al}\left(\mathrm{BO}_{2}\right)_{4}{ }^{-}$(whose $\mathrm{VDE}=8.28 \mathrm{eV}$ ) where a trivalent main group atom plays the role of central core.

\section{$3.2 \mathrm{Ti}\left(\mathrm{BO}_{2}\right)_{n}{ }^{-}(n=1-5)$ and $\mathrm{V}\left(\mathrm{BO}_{2}\right)_{n}{ }^{-}(n=1-6)$}

Next to Sc, the Ti and V atoms have electron configurations of $[\mathrm{Ar}] 3 \mathrm{~d}^{2} 4 \mathrm{~s}^{2}$ and $[\mathrm{Ar}] 3 \mathrm{~d}^{3} 4 \mathrm{~s}^{2}$ and possess maximum valence of +4 
and +5 , respectively. To reveal how many $\mathrm{BO}_{2}$ ligands $\mathrm{Ti}$ and $\mathrm{V}$ require to qualify their borates for being classified as hyperhalogens, the evolution of VDE values of the $\mathrm{Ti}\left(\mathrm{BO}_{2}\right)_{n}{ }^{-}(n=1-5)$ and $\mathrm{V}\left(\mathrm{BO}_{2}\right)_{n}{ }^{-}(n=1-6)$ systems were also studied in this work. Based on above analysis, all the lowest-lying $\mathrm{Sc}\left(\mathrm{BO}_{2}\right)_{n}{ }^{-}$isomers feature a structure where the $\mathrm{BO}_{2}$ ligands spread apart and each binds with the central Sc atom through a Sc-O bond. In view of this, only the isomers with separated $\mathrm{BO}_{2}$ ligands were considered for the $\mathrm{Ti}\left(\mathrm{BO}_{2}\right)_{n}{ }^{-}(n=1-5)$ and $\mathrm{V}\left(\mathrm{BO}_{2}\right)_{n}{ }^{-}(n=1-6)$ anions. These structures, together with their corresponding neutral ones, were optimized by the M06 method. Different spin multiplicities were taken into account during optimizations. Note that the neutral $\mathrm{Ti}\left(\mathrm{BO}_{2}\right)_{n}(n=1-5)$ and $\mathrm{V}\left(\mathrm{BO}_{2}\right)_{n}(n=1-6)$ configurations were obtained on the basis of their corresponding anionic structures instead of a thorough structure searching. They are possibly local, but not global minima on the potential energy surfaces.

3.2.1 Geometry and magnetism. The optimized structures of $\mathrm{Ti}\left(\mathrm{BO}_{2}\right)_{n}{ }^{-}$and their corresponding neutral $\mathrm{Ti}\left(\mathrm{BO}_{2}\right)_{n}$ are shown in Fig. 3 and 4, respectively, while those of the anionic $\mathrm{V}\left(\mathrm{BO}_{2}\right)_{n}{ }^{-}$and neutral $\mathrm{V}\left(\mathrm{BO}_{2}\right)_{n}$ are presented in Fig. 5 and 6, respectively. The nomenclature uses symbol of element plus Arabic numerals from 1 to 6 to indicate the number of involved $\mathrm{BO}_{2}$ ligands, followed by s, $\mathrm{d}, \mathrm{t}, \mathrm{q}$, quintet, and sextet to denote the spin state (singlet, doublet, ...). To illuminate electronic structure of the resulting borates, some selected molecular orbitals are shown in Fig. S1 (ESI $\dagger$ ).

Three structures with different spin states (singlet, triplet, quintet) were found for $\operatorname{Ti}\left(\mathrm{BO}_{2}\right)^{-}$. The singlet isomer is linear, while the other two are slightly bent. It can be found from Fig. 3 and Table 3 that, the isomer where the Ti atom maintains its spin is the most stable, followed by that in a higher spin state, while the one with a total spin state of zero is the least favorable. For example, the stability order is Ti1-t $>$ Ti1-quintet $>$ Ti1-s. The same is valid for the $\operatorname{Ti}\left(\mathrm{BO}_{2}\right)_{2}{ }^{-}$and $\operatorname{Ti}\left(\mathrm{BO}_{2}\right)_{3}{ }^{-}$isomers. That is, the Ti2-q and Ti3-t isomers with two unpaired d electrons from Ti are 3.0 and $17.3 \mathrm{kcal} \mathrm{mol}^{-1}$ more stable than Ti2-d and Ti3-s, respectively. Due to Jahn-Teller effect, Ti3-t has $C_{2 v}$ instead of $D_{3 \mathrm{~h}}$ symmetry and the symmetry of Ti4-d is lowered to $D_{2 \mathrm{~d}}$ compared with the lowest-lying structure of $\mathrm{Sc}\left(\mathrm{BO}_{2}\right)_{4}{ }^{-}$. In contrast, Ti3-s and its corresponding neutral Ti3'-d hold $D_{3 \mathrm{~h}}$ symmetry. Likewise, Ti5-s possesses a trigonal bipyramidal geometry with $D_{3 \mathrm{~h}}$ symmetry. The structures of neutral $\mathrm{Ti}\left(\mathrm{BO}_{2}\right)_{n}$ basically resemble those of their corresponding anions. The only exception here is $\mathbf{T i 5}^{\prime}-\mathbf{d}$, in which two $\mathrm{BO}_{2}$ ligands are combined together.

From Fig. 5 and Table 3, the $\mathrm{V}$ atom maintains its spin in the lowest-lying isomer of $\mathrm{V}\left(\mathrm{BO}_{2}\right)^{-}$, namely V1-q. Consequently, it has a magnetic moment of $3 \mu_{\mathrm{B}}$. High-spin isomer V1-sextet and low-spin isomer V1-d are 5.8 and $71.7 \mathrm{kcal} \mathrm{mol}^{-1}$ higher in energy than V1-q, respectively. All three structures of $\mathrm{V}\left(\mathrm{BO}_{2}\right)_{2}{ }^{-}$ are linear with $D_{\infty \mathrm{h}}$ symmetry. The magnetic moment is $4 \mu_{\mathrm{B}}$ for the lowest-energy configuration V2-quintet. The electronic structure characteristics of both $\mathrm{Ti}\left(\mathrm{BO}_{2}\right)_{n}{ }^{-}$and $\mathrm{V}\left(\mathrm{BO}_{2}\right)_{n}{ }^{-}$species indicate that the central transition metal atoms are inclined to keep the intrinsic electronic state in their borates. For $\mathrm{V}\left(\mathrm{BO}_{2}\right)_{n}{ }^{-}$ $(n=3-6)$, the $\mathrm{BO}_{2}$ ligands are distributed individually in each cluster. Obviously, Jahn-Teller distortion also appears in the

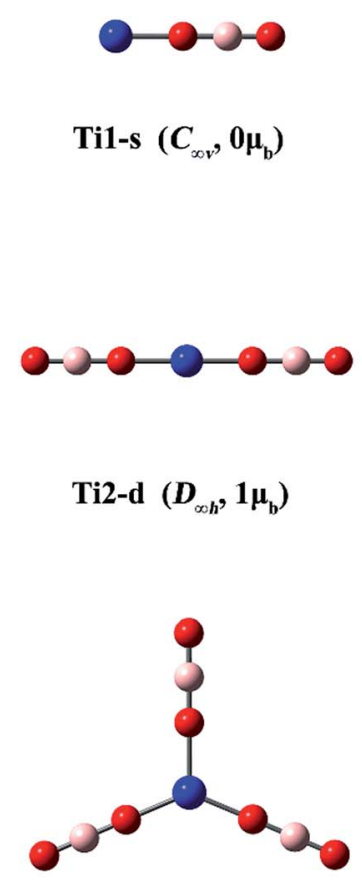

Ti3-t $\left(C_{2 v}, 2 \mu_{\mathrm{b}}\right)$

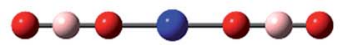

Ti2-q $\left(D_{\infty h}, 3 \mu_{b}\right)$

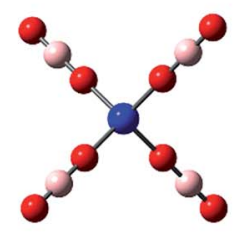

Ti4-d $\left(D_{2 d}, 1 \mu_{\mathrm{b}}\right)$

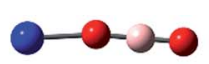

Ti1-quintet $\left(C_{1}, 4 \mu_{\mathrm{b}}\right)$

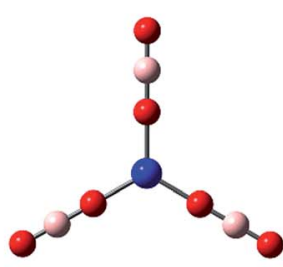

Ti3-s $\left(D_{3 h}, 0 \mu_{b}\right)$

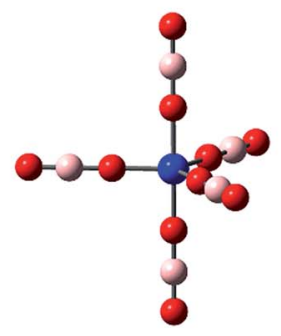

Ti5-s $\left(D_{3 h}, 0 \mu_{b}\right)$

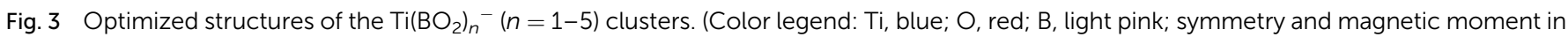
parentheses.) 


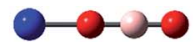

Ti1'-d $\left(C_{\alpha \nu}, 1 \mu_{\mathrm{b}}\right)$

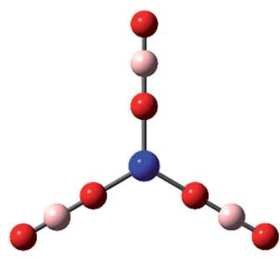

Ti3'-d $\left(D_{3 h}, 1 \mu_{\mathrm{b}}\right)$

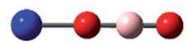

Ti1'-q $\left(C_{1}, 3 \mu_{\mathrm{b}}\right)$

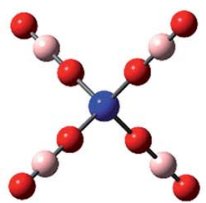

Ti4's $\left(T_{d}, 0 \mu_{b}\right)$

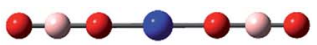

Ti2'-t $\left(D_{\infty\llcorner}, 2 \mu_{\mathrm{b}}\right)$

Fig. 4 Optimized structures of the $\mathrm{Ti}\left(\mathrm{BO}_{2}\right)_{n}(n=1-5)$ clusters. (Color legend: Ti, blue; O, red; $\mathrm{B}$, light pink; symmetry and magnetic moment in parentheses.)

$\mathrm{V}\left(\mathrm{BO}_{2}\right)_{n}{ }^{-}$series. The geometry of V3-q is still of $D_{3 \mathrm{~h}}$-symmetry. In contrast, both V4-t and V4-s are distorted to $D_{2 \mathrm{~d}^{-}}$-symmetry as the $\mathrm{V}$ atom possesses two $\mathrm{d}$ electrons therein. V5-d is lowered to $\mathrm{C}_{2}$-symmetry because the $\mathrm{V}$ atom has one d electron left. Similar to the case of 4a and Ti5-s, V6-s does not have d electron from the central metal atom, so it appears to be a regular octahedron with $O_{\mathrm{h}}$-symmetry. As for the neutral $\mathrm{V}\left(\mathrm{BO}_{2}\right)_{n}$ clusters, the $\mathrm{BO}_{2}$ ligands are also isolated in every structure except that two $\mathrm{BO}_{2}$ ligands dimerized in $\mathbf{V} \mathbf{6}^{\prime}$-d.

From Table 3, the zero-point-corrected dissociation energies of $\mathrm{Ti}\left(\mathrm{BO}_{2}\right)_{n}{ }^{-}$and $\mathrm{V}\left(\mathrm{BO}_{2}\right)_{n}{ }^{-}$are in the range of 26.3-
$141.6 \mathrm{kcal} \mathrm{mol}^{-1}$ and $14.6-139.5 \mathrm{kcal} \mathrm{mol}^{-1}$, respectively, indicating the stability of $\mathrm{Ti}\left(\mathrm{BO}_{2}\right)_{n}{ }^{-}$and $\mathrm{V}\left(\mathrm{BO}_{2}\right)_{n}{ }^{-}$with respect to emission of a $\mathrm{BO}_{2}$ unit.

3.2.2 Vertical electron detachment energy. The VDE and ADE values of $\mathrm{Ti}\left(\mathrm{BO}_{2}\right)_{n}{ }^{-}$and $\mathrm{V}\left(\mathrm{BO}_{2}\right)_{n}{ }^{-}$calculated at the MP2 level are listed in Table 3, where the VDE values from the OVGF method are also listed for comparison. From the table, Ti3-t, Ti4-d, Ti5-s, V2-t, V3-q, V4-s, V4-t, V5-d, and V6-s can be classified as superhalogen anions, among which the Ti3-t, Ti4-d, V2-t, V3-q, V4-t, V5-d isomers with nonzero magnetic moment can be considered as magnetic superhalogens. Besides, the Ti4-d, Ti5-

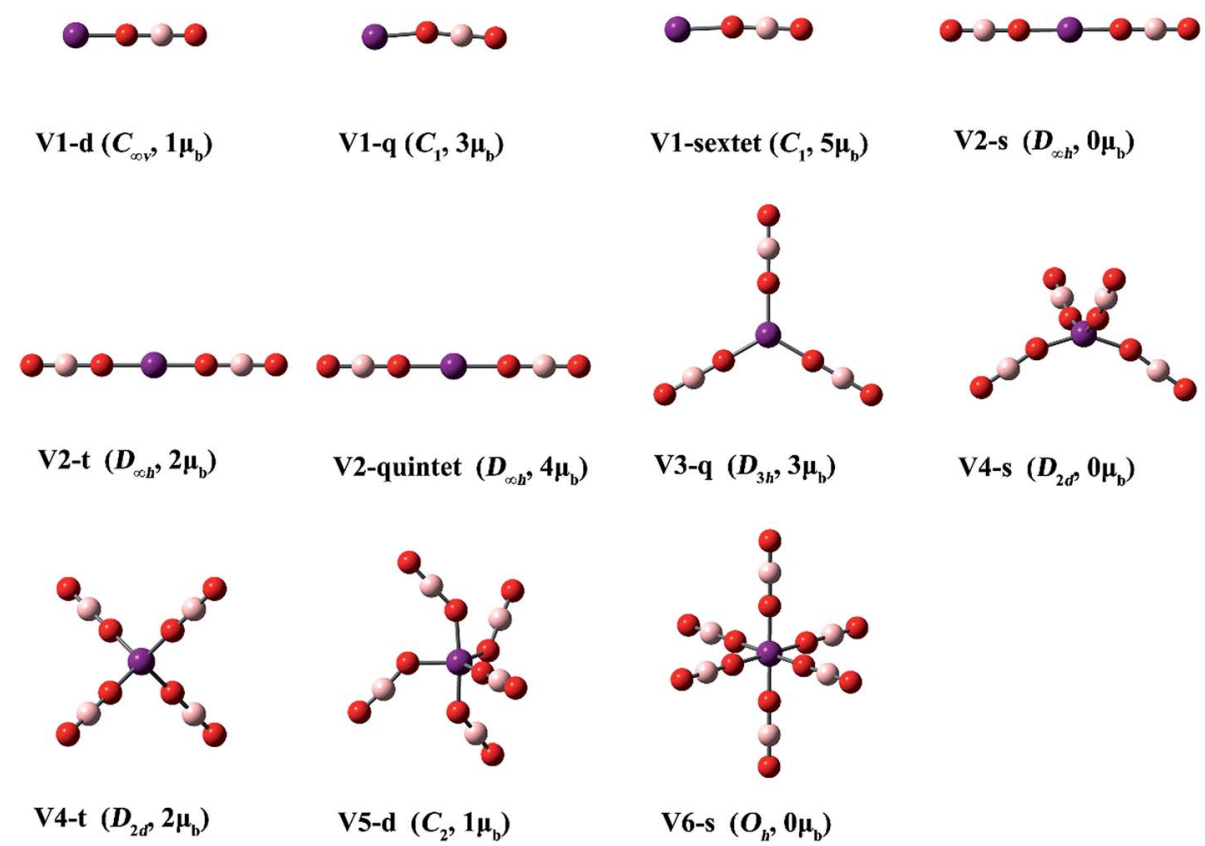

Fig. 5 Optimized structures of the $\mathrm{V}\left(\mathrm{BO}_{2}\right)_{n}{ }^{-}(n=1-6)$ clusters. (Color legend: $\mathrm{V}$, purple; $\mathrm{O}$, red; $\mathrm{B}$, light pink; symmetry and magnetic moment in parentheses.) 

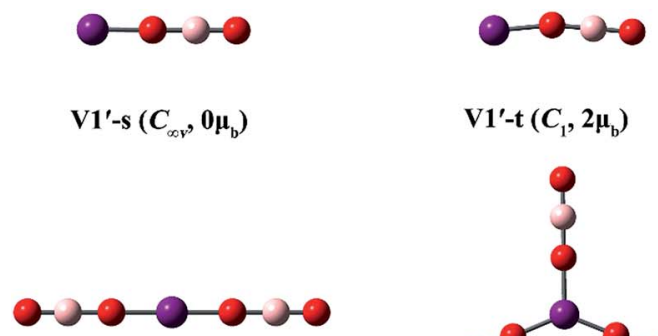

$$
V 1 '-t\left(C_{1}, 2 \mu_{b}\right)
$$

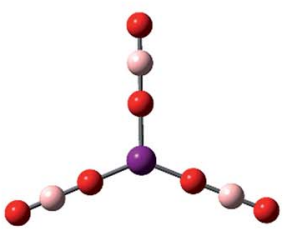

$V 2^{\prime}-q\left(D_{\circ o h}, 3 \mu_{\mathrm{b}}\right)$

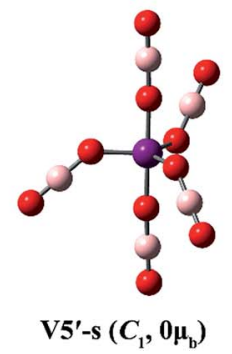

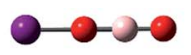

V1'-quintet $\left(C_{s}, 4 \mu_{\mathrm{b}}\right)$

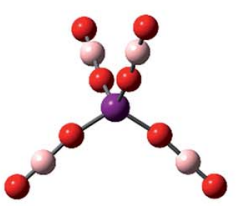

V4'-d $\left(C_{1}, 1 \mu_{\mathrm{b}}\right)$

Fig. 6 Optimized structures of the $\mathrm{V}\left(\mathrm{BO}_{2}\right)_{n}(n=1-6)$ clusters. (Color legend: $\mathrm{V}$, purple; $\mathrm{O}$, red; $\mathrm{B}$, light pink; symmetry and magnetic moment in parentheses.)

Table 3 Relative energy $\left(E_{\text {rel, }}\right.$ in $\left.\mathrm{kcal} \mathrm{mol}^{-1}\right)$, vertical detachment energies (VDEs, in eV), and adiabatic detachment energies (ADEs, in eV) of $\mathrm{Ti}\left(\mathrm{BO}_{2}\right)_{n}{ }^{-}(n=1-5)$ and $\mathrm{V}\left(\mathrm{BO}_{2}\right)_{n}{ }^{-}(n=1-6)$. Pole strengths (PS) in parentheses. Dissociation energies $\left(D_{\mathrm{e}}\right.$, in $\left.\mathrm{kcal} \mathrm{mol}^{-1}\right)$ of the $\mathrm{TM}\left(\mathrm{BO}_{2}\right)_{n}{ }^{-}$ $\rightarrow \mathrm{TM}\left(\mathrm{BO}_{2}\right)_{n-1}{ }^{-}+\mathrm{BO}_{2}(\mathrm{TM}=\mathrm{Ti}, \mathrm{V})$ reactions

\begin{tabular}{lllllr}
\hline Species & $E_{\text {rel }}$ & $\mathrm{VDE}^{\mathrm{OVGF}}$ & $\mathrm{VDE}^{\mathrm{MP} 2}$ & $\mathrm{ADE}^{\mathrm{MP2}}$ & \multicolumn{1}{c}{$D_{\mathrm{e}}$} \\
\hline Ti1-s & 23.5 & $1.57(0.885)$ & 1.25 & 0.66 & 28.5 \\
Ti1-t & 0.0 & $1.77(0.864)$ & 1.76 & 1.68 & 53.4 \\
Ti1-quintet & 9.9 & $1.26(0.922)$ & 0.62 & 0.61 & 26.3 \\
Ti2-d & 3.0 & $3.08(0.815)$ & 3.67 & 3.58 & 141.6 \\
Ti2-q & 0.0 & $2.06(0.960)$ & 1.65 & 1.61 & 136.1 \\
Ti3-s & 17.3 & $2.95(0.878)$ & 2.58 & 2.07 & 126.9 \\
Ti3-t & 0.0 & $4.20(0.922)$ & 3.71 & 2.82 & 130.1 \\
Ti4-d & - & $6.66(0.889)$ & 4.86 & 4.11 & 126.3 \\
Ti5-s & - & $9.23(0.911)$ & 9.30 & 6.29 & 94.1 \\
V1-d & 71.7 & $2.01(0.854)$ & 0.93 & 0.91 & 14.6 \\
V1-q & 0.0 & $1.95(0.858)$ & 3.03 & 2.98 & 59.5 \\
V1-sextet & 5.8 & $1.49(0.983)$ & 0.97 & 0.86 & 45.6 \\
V2-s & 44.3 & $2.49(0.849)$ & 2.54 & 2.44 & 107.5 \\
V2-t & 24.6 & $4.46(0.811)$ & 3.62 & 3.30 & 139.5 \\
V2-quintet & 0.0 & $2.38(0.957)$ & 2.11 & 2.06 & 134.2 \\
V3-q & - & $5.18(0.908)$ & 5.10 & 4.02 & 127.9 \\
V4-s & 49.7 & $7.38(0.882)$ & 7.23 & 3.68 & 68.1 \\
V4-t & 0.0 & $8.44(0.906)$ & 8.72 & 5.84 & 95.5 \\
V5-d & - & $9.09(0.909)$ & 9.27 & 5.62 & 93.6 \\
V6-s & - & $9.44(0.910)$ & 8.23 & 5.87 & 46.2 \\
& & & & &
\end{tabular}

s, V3-q, V4-s, V4-t, V5-d and V6-s species possess larger VDE values than that of $\mathrm{BO}_{2}^{-}$and can be termed hyperhalogen anions. In a word, with $\mathrm{Sc}, \mathrm{Ti}$, and $\mathrm{V}$ as central atoms, it requires at least four, four, and three $\mathrm{BO}_{2}$ ligands, respectively, to qualify the resulting $\mathrm{TM}\left(\mathrm{BO}_{2}\right)_{n}{ }^{-}$( $\mathrm{TM}=\mathrm{Sc}$, Ti, and $\left.\mathrm{V}\right)$ clusters to be considered as hyperhalogens. From Table 3, it is noted that the $\mathrm{VDE}^{\mathrm{MP} 2}$ values of $\mathrm{Ti}\left(\mathrm{BO}_{2}\right)_{n}{ }^{-}$show a sharp increase from
$\mathrm{Ti}\left(\mathrm{BO}_{2}\right)_{4}{ }^{-}$to $\mathrm{Ti}\left(\mathrm{BO}_{2}\right)_{5}{ }^{-}$. Such a sudden rise of VDE value is believed to root in the maximum valence state of +4 of the $\mathrm{Ti}$ atom. However, the same increase doesn't appear in the $\mathrm{V}\left(\mathrm{BO}_{2}\right)_{n}{ }^{-}$series. From Table $\mathrm{S} 1, \dagger$ the VDE values of $\mathrm{TMF}_{n}{ }^{-}(\mathrm{TM}$ $=\mathrm{Sc}$, Ti, $\mathrm{V}$ ) can be more or less enhanced by replacing fluorine with $\mathrm{BO}_{2}$ ligands. ${ }^{50}$

\section{Conclusions}

The structural, electronic and magnetic properties of three series of early-transition-metal borates, namely $\mathrm{Sc}\left(\mathrm{BO}_{2}\right)_{n}{ }^{-10}(n=1-4)$, $\operatorname{Ti}\left(\mathrm{BO}_{2}\right)_{n}{ }^{-10}(n=1-5)$, and $\mathrm{V}\left(\mathrm{BO}_{2}\right)_{n}{ }^{-/ 0}(n=1-6)$, were studied by performing density functional theory and $a b$ initio calculations. In view of the positive dissociation energies, all studied anionic clusters are stable against the loss of $\mathrm{a} \mathrm{BO}_{2}$ ligand.

The lowest-lying $\mathrm{Sc}\left(\mathrm{BO}_{2}\right)_{n}{ }^{-}$isomers feature a structure where the $\mathrm{BO}_{2}$ ligands spread apart, whereas the $\mathrm{BO}_{2}$ ligands begin to combine into a trimer in the lowest-energy $\mathrm{Sc}\left(\mathrm{BO}_{2}\right)_{4}$ structure. This can be related to the maximum valence state of +3 of the Sc atom. By the same token, there is a sharp increase in VDE value from $\mathrm{Sc}\left(\mathrm{BO}_{2}\right)_{3}{ }^{-}$to $\mathrm{Sc}\left(\mathrm{BO}_{2}\right)_{4}{ }^{-}$, and the latter species can be classified as hyperhalogens since they possess larger VDE values than that of its superhalogen ligand $\mathrm{BO}_{2}{ }^{-}$. As for Ti and $\mathrm{V}$ atoms, they require four and three $\mathrm{BO}_{2}$ ligands, respectively, to enable their borates to be termed hyperhalogen. Besides, the Ti4-d, V3-q, V4-t, and V5-d species can be considered as magnetic hyperhalogens owing to their nonzero magnetic moment.

\section{Conflicts of interest}

There are no conflicts of interest to declare. 


\section{Acknowledgements}

This work was supported by the National Natural Science Foundation of China (Grant No. 21603032, 21375017), State Key Development Program for Basic Research of China (Grant No. 2013CB834801), Natural Science Foundation of Fujian Province (Grant No. 2016J05032), and MiaoPu Foundation of Fujian Medical University (Grant No. 2015MP034).

\section{References}

1 H. Hotop and W. C. Lineberger, J. Phys. Chem. Ref. Data, 1985, 14, 731.

2 N. Bartlett, Proc. Chem. Soc., London, 1962, 6, 218.

3 N. Bartlett and D. H. Lohmann, J. Chem. Soc., 1962, 5253.

4 G. L. Gutsev and A. I. Boldyrev, Chem. Phys., 1981, 56, 277.

5 X.-B. Wang, C.-F. Ding, L.-S. Wang, A. I. Boldyrev and J. Simons, J. Chem. Phys., 1999, 110, 4763.

6 I. Anusiewicz and P. Skurski, Chem. Phys. Lett., 2002, 358, 426.

7 I. Anusiewicz, M. Sobczyk, I. Dąbkowska and P. Skurski, Chem. Phys., 2003, 291, 171.

8 B. M. Elliott, E. Koyle, A. I. Boldyrev, X.-B. Wang and L.-S. Wang, J. Phys. Chem. A, 2005, 109, 11560.

9 J. Yang, X.-B. Wang, X.-P. Xing and L.-S. Wang, J. Chem. Phys., 2008, 128, 201102.

10 M. Sobczyk, A. Sawicka and P. Skurski, Eur. J. Inorg. Chem., 2003, 2003, 3790.

11 I. Anusiewicz and P. Skurski, Chem. Phys. Lett., 2007, 440, 41. 12 S. Freza and P. Skurski, Chem. Phys. Lett., 2010, 487, 19.

13 G. L. Gutsev, B. K. Rao, P. Jena, X.-B. Wang and L.-S. Wang, Chem. Phys. Lett., 1999, 312, 598.

14 G. L. Gutsev, P. Jena, H.-J. Zhai and L.-S. Wang, J. Chem. Phys., 2001, 115, 7935.

15 H.-J. Zhai, L.-M. Wang, S.-D. Li and L.-S. Wang, J. Phys. Chem. A, 2007, 111, 1030.

16 K. Pradhan and P. Jena, J. Chem. Phys., 2011, 135, 144305.

17 H. Wen, G.-L. Hou, W. Huang, N. Govind and X.-B. Wang, J. Chem. Phys., 2011, 135, 184309.

18 L.-J. Zhao, H.-G. Xu, G. Feng, P. Wang, X.-L. Xu and W.-J. Zheng, Phys. Chem. Chem. Phys., 2016, 18, 6175.

19 I. Anusiewicz, J. Phys. Chem. A, 2009, 113, 6511.

20 J. Zhang, P. Yang, Z.-R. Sun and X.-B. Wang, J. Phys. Chem. A, 2014, 118, 8074.

21 I. Anusiewicz, J. Phys. Chem. A, 2009, 113, 11429.

22 M. Czapla, S. Freza and P. Skurski, Chem. Phys. Lett., 2015, 619, 32.

23 M. Marchaj, S. Freza, O. Rybacka and P. Skurski, Chem. Phys. Lett., 2013, 574, 13.

24 Y. Li, D. Wu and Z.-R. Li, Inorg. Chem., 2008, 47, 9773.

25 T. Zhao, S. Zhang, Q. Wang, Y. Kawazoe and P. Jena, Phys. Chem. Chem. Phys., 2014, 16, 22979.

26 M. Marchaj, S. Freza and P. Skurski, Chem. Phys. Lett., 2014, 612, 172.

27 S. Giri, S. Behera and P. Jena, Angew. Chem., Int. Ed., 2014, 126, 14136.
28 O. Tutusaus, R. Mohtadi, T. S. Arthur, F. Mizuno, E. G. Nelson and Y. V. Sevryugina, Angew. Chem., Int. Ed., 2015, 54, 7900.

29 H. Zhao, J. Zhou, H. Fang and P. Jena, ChemPhysChem, 2016, 17, 184.

30 T.-s. Zhao, J. Zhou, Q. Wang and P. Jena, J. Phys. Chem. Lett., 2016, 7, 2689.

31 M. Willis, M. Götz, A. K. Kandalam, G. F. Ganteför and P. Jena, Angew. Chem., Int. Ed., 2010, 49, 8966.

32 Y. Feng, H.-G. Xu, W. Zheng, H. Zhao, A. K. Kandalam and P. Jena, J. Chem. Phys., 2011, 134, 094309.

33 G. L. Gutsev, C. A. Weatherford, L. E. Johnson and P. Jena, J. Comput. Chem., 2012, 33, 416.

34 H. Chen, X.-Y. Kong, W. Zheng, J. Yao, A. K. Kandalam and P. Jena, ChemPhysChem, 2013, 14, 3303.

35 C. Paduani and P. Jena, J. Phys. Chem. A, 2012, 116, 1469.

36 C. Paduani and P. Jena, J. Nanopart. Res., 2012, 14, 1035.

37 C. Paduani, M. M. Wu, M. Willis and P. Jena, J. Phys. Chem. A, 2011, 115, 10237.

38 G.-L. Hou, M. M. Wu, H. Wen, Q. Sun, X.-B. Wang and W.-J. Zheng, J. Chem. Phys., 2013, 139, 044312.

39 P. Koirala, K. Pradhan, A. K. Kandalam and P. Jena, J. Phys. Chem. A, 2013, 117, 1310.

40 W.-M. Sun, X.-H. Li, Y. Li, D. Wu, C.-Y. Li, J.-H. Chen and Z.-R. Li, ChemPhysChem, 2016, 17, 1468.

41 W.-M. Sun, D. Hou, D. Wu, X.-H. Li, Y. Li, J.-H. Chen, C.-Y. Li and Z.-R. Li, Dalton Trans., 2015, 44, 19901.

42 Y. Zhao and D. G. Truhlar, J. Phys. Chem. A, 2006, 110, 13126.

43 A. E. Reed, R. B. Weinstock and F. Weinhold, J. Chem. Phys., 1985, 83, 735.

44 L. S. Cederbaum, J. Phys. B: At. Mol. Phys., 1975, 8, 290.

45 J. V. Ortiz, J. Chem. Phys., 1988, 89, 6348.

46 V. G. Zakrzewski, W. v. Niessen, A. I. Boldyrev and P. v. R. Schleyer, Chem. Phys., 1993, 174, 167.

47 V. G. Zakrzewski, O. Dolgounitcheva and J. V. Ortiz, J. Chem. Phys., 1996, 105, 5872.

48 M. J. Frisch, G. W. Trucks, H. B. Schlegel, G. E. Scuseria, M. A. Robb, J. R. Cheeseman, V. B. G. Scalmani, B. Mennucci, G. A. Petersson, H. Nakatsuji, M. Caricato, X. Li, H. P. Hratchian, A. F. Izmaylov, J. Bloino, G. Zheng, J. L. Sonnenberg, M. Hada, M. Ehara, K. Toyota, R. Fukuda, J. Hasegawa, M. Ishida, T. Nakajima, Y. Honda, O. Kitao, H. Nakai, T. Vreven, J. A. Montgomery, J. E. Peralta Jr, F. Ogliaro, M. Bearpark, J. J. Heyd, E. Brothers, K. N. Kudin, V. N. Staroverov, R. Kobayashi, J. Normand, K. Raghavachari, A. Rendell, J. C. Burant, S. S. Iyengar, J. Tomasi, M. Cossi, N. Rega, J. M. Millam, M. Klene, J. E. Knox, J. B. Cross, V. Bakken, C. Adamo, J. Jaramillo, R. Gomperts, R. E. Stratmann, O. Yazyev, A. J. Austin, R. Cammi, C. Pomelli, J. W. Ochterski, R. L. Martin, K. Morokuma, V. G. Zakrzewski, G. A. Voth, P. Salvador, J. J. Dannenberg, S. Dapprich, A. D. Daniels, O. Farkas, J. B. Foresman, J. V. Ortiz, J. Cioslowski and D. J. Fox, GAUSSIAN 09, Revision D.01, Gaussian, Inc, Wallingford CT, 2009. 
49 R. Dennington, T. Keith and J. Millam, GaussView, Version 5.09, Semichem Inc., Shawnee Mission, KS, 2009.

50 K. Pradhan, G. L. Gutsev and P. Jena, J. Chem. Phys., 2010, 133, 144301.
51 A. K. Kandalam, B. Kiran, P. Jena, S. Pietsch and G. Gantefor, Phys. Chem. Chem. Phys., 2015, 17, 26589.

52 Y.-Z. Liu, J. Zhou and P. Jena, J. Phys. Chem. C, 2015, 119, 11056. 